Trinity University

Digital Commons @ Trinity

Engineering Faculty Research

Engineering Science Department

2019

Collagen Based Multicomponent Interpenetrating Networks as

Promising Scaffolds for 3D Culture of Human Neural Stem Cells, Human Astrocytes, and Human Microglia

\author{
Rachel Van Drunen \\ Trinity University, rvandrun@trinity.edu \\ Andrea C. Jimenez-Vergara \\ Trinity University, ajimene1@trinity.edu \\ Erin H. Tsai \\ Trinity University, etsai@trinity.edu \\ Rachel Tchen \\ Trinity University, rtchen@trinity.edu \\ Tyler Cagle \\ Trinity University, tcagle@trinity.edu
}

See next page for additional authors

Follow this and additional works at: https://digitalcommons.trinity.edu/engine_faculty

Part of the Engineering Commons

\footnotetext{
Repository Citation

Van Drunen, R., Jimenez-Vergara, A. C., Tsai, E. H., Tchen, R., Cagle, T., Agee, A. B., . . Munoz-Pinto, D. J. (2019). Collagen Based Multicomponent Interpenetrating Networks as Promising Scaffolds for 3D Culture of Human Neural Stem Cells, Human Astrocytes, and Human Microglia. ACS Applied Bio Materials, 2(3), 975-980. doi:10.1021/acsabm.8b00783
}

This Post-Print is brought to you for free and open access by the Engineering Science Department at Digital Commons @ Trinity. It has been accepted for inclusion in Engineering Faculty Research by an authorized administrator of Digital Commons @ Trinity. For more information, please contact jcostanz@trinity.edu. 


\section{Authors}

Rachel Van Drunen, Andrea C. Jimenez-Vergara, Erin H. Tsai, Rachel Tchen, Tyler Cagle, Anne B. Agee, James Roberts, Jennifer M. Steele, and Dany J. Munoz Pinto 
This document is the unedited Author's version of a Submitted Work that was subsequently accepted for publication in ACS Appl. Bio Mater. 2019, 2, 975-980. DOI:10.1021/acsabm.8b00783, copyright $\odot$ American Chemical Society after peer review. To access the final edited and published work, see https://pubs.acs.org/doi/abs/10.1021/acsabm.8b00783

\title{
Collagen Based Multicomponent Interpenetrating Networks as Promising Scaffolds for the 3D Culture of Human Neural Stem Cells, Human Astrocytes, and Human Microglia
}

Rachel Van Drunen ${ }^{1}$, Andrea C. Jimenez-Vergara ${ }^{2}$, Erin H. Tsai ${ }^{3}$, Rachel Tchen ${ }^{1}$, Tyler Cagle ${ }^{1}$, Anne B. Agee $^{3}$, James Roberts ${ }^{1}$, Jennifer M. Steele ${ }^{4}$ and Dany J. Munoz-Pinto ${ }^{1,2^{*}}$

\author{
${ }^{1}$ Neuroscience Program, Trinity University, San Antonio, TX 78212, United States \\ ${ }^{2}$ Engineering Science Department, Trinity University, San Antonio, TX 78212, United States \\ ${ }^{3}$ Chemistry Department, Trinity University, San Antonio, TX 78212, United States \\ ${ }^{4}$ Physics and Astronomy Department, Trinity University, San Antonio, TX 78212, United States
}

\author{
*Corresponding author: \\ Department of Engineering Science, Neuroscience Program \\ Center for the Sciences and Innovation, CSI 470C \\ Trinity University \\ One Trinity Place \\ San Antonio, TX 78212 \\ Tel: 1-(210)-999-7565 \\ Fax: 1-(210)-999-8037 \\ E-mail: dmunozpi@trinity.edu
}

Keywords: interpenetrating networks, neural stem cells, astrocytes, and microglia 


\begin{abstract}
This work describes for first time the fabrication and characterization of multicomponent interpenetrating networks composed of collagen I, hyaluronic acid, and poly(ethylene glycol) diacrylate for the 3D culture of human neural stem cells, astrocytes, and microglia. The chemical composition of the scaffolds can be modulated while maintaining values of complex moduli within the range of the mechanical performance of brain tissue $(\approx 6.9 \mathrm{kPa})$ and having cell viability exceeding $84 \%$. The developed scaffolds are a promising new family of biomaterials that can potentially serve as $3 \mathrm{D}$ in vitro models for studying the physiology and physiopathology of the central nervous system.
\end{abstract}


Neurons, astrocytes, and microglia are three of the main cell types present in the central nervous system (CNS). They are the central focus of attention in the study of CNS physiology and the development of neurological pathologies including Alzheimers' disease (AD), Parkinson's disease (PD) and amyotrophic lateral sclerosis (ALS) among others ${ }^{1-5}$. Numerous in vitro neuronal models rely upon the culture of these cells on plastic or glass-based surfaces. These 2D platforms, however, are poor representations of the natural cell milieu since they fail to recapitulate key aspects of the $3 \mathrm{D}$ microarchitecture of native tissue ${ }^{6}$. In addition, cells in 2D models experience surfaces with rigidity values orders of magnitude greater than the rigidity present in native tissue. Moreover, in $2 \mathrm{D}$ environments the presence of diffusional limitations for the exchange of nutrients, waste products, or the accumulation of extracellular matrix (ECM) components is either restricted or nonexistent ${ }^{7}$. This drawback directly restrains studies focused on the production and accumulation of amyloid beta or tau proteins, both of which are the most recognized ECM indicators of AD progression ${ }^{8-9}$. In short, cellular responses procured from 2D platforms cannot be directly extrapolated into 3D contexts ${ }^{10}$. Therefore, there is still a need for the development of novel scaffolds with the capacity to support the 3D culture of human CNS cells. Ideally, 3D scaffolds should have the capacity to be fine-tuned to recapitulate similar chemical and mechanical properties to those of central nervous tissue.

Multicomponent interpenetrating networks (mIPNs) offer a promising alternative to these demands as they have the potential to present mechanically compliant scaffolds whose high water content and chemical composition resembles soft tissue ${ }^{11}$. While numerous approaches have been taken to utilize mIPN hydrogels to address the demand for biocompatible 3D neural scaffolds, only a few studies have tailored their biomaterials towards multiple neural cell types ${ }^{12-13}$. In this work, our team developed, characterized and evaluated a new family of mIPNs as potential 3D scaffolds for the culture of human CNS cells. Since obtaining neurons in high numbers is challenging, we used neural stem cells as one of 
our cell models. These cells have the capacity to differentiate into neuron-like cells in large quantities ${ }^{6}$, ${ }^{14}$. Neural stem cells (Human iPSC-Derived Neural Stem Cells, iHNSCs) were commercially obtained from Cell Applications and used at passage four. In addition to neural stem cells, we also utilized human astrocytes (HAf, Cell Applications) at passage five, and the human microglia cell line (HMC3, ATCC) as our cell models. The three cell types were cultured and expanded in vitro following the general recommendation and culture protocols provided by the seller. The proposed bioinspired mIPNs were fabricated using collagen type I (Col I, BD Biosciences), hyaluronic acid (HA, Lifecore Biomedical, 1,300 $\mathrm{kDa}$ ) and poly(ethylene glycol) diacrylate (PEGDA, Sigma) of varying molecular weights (MW). Although these three components have been extensively utilized as hydrogel scaffolds in biomedical applications, to the best of our knowledge, this is the first time they have been combined in a sequential fashion to fabricate mIPN structures that support the 3D culture of three of the main cell types in the CNS. Collagen I was selected due to its self-assembling properties, its similar chemical composition to collagen type IV, the primary collagen type in the CNS, and because it has been previously employed in modeling in vitro systems of brain tissue ${ }^{15}$. Hyaluronic acid was chosen because it is the most abundant polysaccharide in CNS tissue ${ }^{15}$ and because it plays an integral role in the physiology of the $\mathrm{CNS}^{16}$. Finally, PEGDA was also employed due to its well established biocompatibility, its biological blank slate behavior, its resistance to cell mediated contraction and degradation ${ }^{17}$, and because, by varying its concentration and MW, the overall mechanical performance of the scaffolds can be fine-tuned ${ }^{18-21}$. PEGDA of varying MW was synthesized following the methods described by Jimenez-Vergara et al. ${ }^{18}$.

To fabricate the mIPNs scaffolds described in Table 1, we first assembled a semi-IPN structure using Col I at $3.0 \mathrm{mg} / \mathrm{mL}$ and $\mathrm{HA}$ from 0.0 to $2.0 \mathrm{mg} / \mathrm{mL}$. The selected values for the Col I and HA concentrations have been previously used in other hydrogels systems 17, 22-23. Three independent encapsulation experiments were performed (one per cell type). In brief, undifferentiated iHNSCs, HAf or 
HMC 3 cells were suspended in an ice-cold Col I-HA solution $(\mathrm{pH} \approx 7.2)$ at $7.5 \mathrm{E} 05$ cell $/ \mathrm{mL}$, and then 300 $\mu \mathrm{L}$ of the cell suspension were placed in 12 -well plate inserts and allowed to crosslink at $37^{\circ} \mathrm{C}$. At neutral $\mathrm{pH}$ and $37^{\circ} \mathrm{C}$, Col I molecules self-assemble into fiber structures physically entrapping the HA molecules ${ }^{24-25}$. Since both Col I and HA are susceptible to cell mediated contraction and degradation, PEGDA was introduced by sequential infiltration following the methods described by Munoz-Pinto et al. to increase the mechanical and physical stability of the scaffolds ${ }^{17}$. In brief, $1.7 \mathrm{~mL}$ of PEGDA solution at $8.24 \%$, $8.82 \%$, or $9.41 \%$ w/w containing HA at the same target hydrogel concentration $(0.0,1.0$ or $2.0 \mathrm{mg} / \mathrm{mL})$, and 1.0 mM Lithium phenyl-2,4,6-trimethylbenzoylphosphinate (LAP) as photoinitiator were placed in contact with the initial Col I-HA hydrogels. The LAP photoinitiator was synthesized following the methods described by Fairbanks et al. ${ }^{26}$. The addition and presence of HA in the infiltration solution prevents the release of the physically entangled HA molecules during the infiltration of the PEGDA. Once the infiltration step is completed, the PEGDA concentration in the hydrogel reaches $7.0 \%, 7.5 \%$ or $8.0 \%$ $\mathrm{w} / \mathrm{w}$ as the result of the contact between the $300 \mathrm{uL} \mathrm{Col} \mathrm{I-HA}$ hydrogel and the $1.7 \mathrm{~mL}$ of the infiltrating solution. Following the infiltration time, the excess of PEGDA solution was removed and the scaffolds exposed to long wave UV light (365 nm, Spectroline transilluminator) for $5 \mathrm{~min}$. Once the mIPN fabrication was completed the constructs were placed in cell culture media. The required infiltration time was estimated by tracking the changes in the complex modulus of the mIPNs. The mechanical characterization of the scaffolds was performed $24 \mathrm{~h}$ after the mIPN fabrication in the absence of cells. The measurements of the complex modulus served as an indirect method to assess the equilibrium for the infiltration of PEGDA molecules. The mIPN7 was selected as a model for this assessment because this formulation contains the highest levels of HA and therefore the highest resistance to diffusion among the testing group. The complex modulus was measured using a TA Instruments Electroforce 3100 mechanical tester. Eight millimeter diameter disks with approximate $1 \mathrm{~mm}$ in height were preloaded with a $2 \mathrm{~g}$ force, indented $100 \mu \mathrm{m}$, and with an oscillation amplitude of $100 \mu \mathrm{m}$. All statistical analyses of the experimental 
results in this work were performed using analysis of variance (ANOVA) with the Tukey's post hoc test. Significant differences between groups were identified and highlighted for $\mathrm{p} \leq 0.05$ (IBM SPSS software). Figure 1 shows the changes in complex modulus of the mIPN7 as a function of the infiltration time. The values for the complex modulus of the scaffold varied between $1.6 \pm 0.3 \mathrm{kPa}$ for the Col-I-HA scaffold and $5.0 \pm 1.0 \mathrm{kPa}$ for scaffolds incubated with PEGDA for four hours. The increase in the complex modulus served as an indirect measurement of the progressive infiltration of PEGDA within the Col IHA network. Scaffolds infiltrated with the PEGDA solution for $4 \mathrm{~h}$ of infiltration exhibited significant differences when compared with the Col I-HA hydrogel and the $1 \mathrm{~h}$ group $(\mathrm{p} \leq 0.02, \mathrm{n}=4)$, but not when compared with the $2 \mathrm{~h}$ group $(\mathrm{p}=0.724, \mathrm{n}=4)$. The steady state behavior of the complex modulus of the mIPN after $2 \mathrm{~h}$ infiltration suggests that $4 \mathrm{~h}$ can be assumed as the equilibrium time of the system. Since cells are exposed to soluble PEGDA and HA molecules during the infiltration of the initial CoI-HA network, extending the infiltration time beyond the $4 \mathrm{~h}$ time point may result in a reduction in the cytocompatibility of the scaffolds. Therefore we selected $4 \mathrm{~h}$ as the infiltration time for the fabrication process of the mIPNs.

To gain insight into the microscopic structure of the proposed mIPNs, we performed scanning electron microscopy (SEM) using a JEOL JSM-6010LA Scanning Electron Microscope on the mIPN7 which contains $3.0 \mathrm{mg} / \mathrm{mL} \mathrm{Col} \mathrm{I,} 2.0 \mathrm{mg} / \mathrm{mL} \mathrm{HA}$ and $7.0 \%$ w/w $3.4 \mathrm{kDa}$ PEGDA. Appropriate controls including a pure Col I, pure PEGDA, and Col I-PEGDA hydrogels were also imaged. The mIPN7 and the controls were fabricated and allowed to swell for $24 \mathrm{~h}$, the specimens were prepared for imaging following a modified protocol from Raub et al. ${ }^{22}$. In brief, the hydrogel specimens were fixed with $10.0 \% \mathrm{v} / \mathrm{v}$ formalin and dehydrated using ethanol and hexamethyldisilazane. Following the dehydration procedure the samples were cut into two pieces and allowed to dry for $24 \mathrm{~h}$. The samples were then stored until use in a desiccator. Prior to imaging, specimens were mounted on SEM sample stages using carbon tape and 
sputter coated with gold to a thickness of $6 \mathrm{~nm}$ using a Cressington 208auto sputter coater. SEM micrographs $(\mathrm{n}=5)$ were taken from the cross-sectional area of each specimen at $5.0 \mathrm{kV}$ and 7,000x magnification. Representative micrograph images are shown in Figure 2. The microscopic landscape of the mIPN (Figure 2D) displayed increasing packing when compared to the Col I-PEGDA, the pure Col I or PEGDA hydrogels (Figure 2C, 2A and 2B) controls. The resulting mIPN microenvironment differs significantly from the pure Col I network which displays the characteristic fiber structures (Figure 2A), and the pure PEGDA network characterized by a dense mesh-like architecture. The addition of HA to the double Col I-PEGDA networks appears to increase packing density of the scaffold.

The presence of Col I and HA was qualitatively confirmed after 14 days using Picrosirius Red (PR, Polysciences) and Alcian Blue (AB, Acros Organics) staining respectively (Figure 3). The 14 day time point has been previously used to evaluate the integrity of similar IPN systems ${ }^{17}$. As expected, the red coloration in the hydrogels was observed in the formulation containing Col I and not significantly detected in the pure PEGDA hydrogel. In addition, the intensity of the blue color increased as the HA content increased in the hydrogels from the $0.0 \mathrm{mg} / \mathrm{mL}$ HA in the PEGDA and mIPN2 to the $2.0 \mathrm{mg} / \mathrm{mL}$ HA in the mIPN7. Furthermore, using visible absorbance spectroscopy, following a modified approach from Frazier et al. ${ }^{27}$, the HA levels in the mIPN7 were also quantitatively evaluated confirming a total HA concentration of approximately $2.1 \pm 0.2 \mathrm{mg} / \mathrm{mL}(\mathrm{n}=3)$. In brief, HA standards and mIPN7 hydrogel samples were digested in $0.1 \mathrm{~N} \mathrm{NaOH}$ and $37^{\circ} \mathrm{C}$ for $72 \mathrm{~h}$. A volume of $100 \mu \mathrm{L}$ of the digested samples or standards solutions were placed in contact with a $1.0 \mathrm{mg} / \mathrm{mL} \mathrm{AB}$ in $3.0 \% \mathrm{v} / \mathrm{v}$ acetic acid solution. The resulting mixture was incubated at room temperature for $30 \mathrm{~min}$, and then centrifuged at 10,000 rpm for $5 \mathrm{~min}$. The supernatant was removed and the pellet dissolved in $400 \mu \mathrm{L}$ of the Blyscan dissociation reagent (Accurate Chemical). The absorbance of each sample and standard was read at $680 \mathrm{~nm}$ using a SpectraMax M4 multi-mode microplate reader. The concentration of HA in the samples was calculated 
by interpolating the absorbance reading in the standard curve. Cumulatively, the microscopic characterization, the staining, and the spectroscopy confirmed the presence of the three network components in the mIPNs.

In terms of mechanical performance, the complex modulus of the mIPN formulations shown in Table 1 was evaluated and compared with the viscoelastic properties of the cortex of mouse brain (MB). Tissue samples were donated by Dr. James Roberts' laboratory. Cerebral cortex samples were collected from mice in accordance with general NIH guidelines for the use and care of animals in research and the approval of the Trinity University Animal Care and Use Committee (IACUC). Figures 4A-4C show the complex moduli of mIPNs with different HA content: 0.0, 1.0, and $2.0 \mathrm{mg} / \mathrm{mL}$ respectively. As expected, the incorporation of PEGDA dominates the mechanical behavior of the scaffolds. By either increasing the MW of PEGDA, or by reducing its concentration, the resulting scaffolds exhibited a reduction in their complex modulus. This observation is in agreement with previously reported literature ${ }^{17-19,28}$. In Figure 4A, the complex modulus of the mIPN containing $20.0 \mathrm{kDa}$ PEGDA (mIPN1) was $4.2 \mathrm{kPa}$ while the mIPN2 (10.0 kDa PEGDA) exhibited a modulus of $7.4 \mathrm{kPa}$. The modulus of the mIPN1 was significantly lower than the modulus in the MB tissue or the mIPN2 $(\mathrm{p} \leq 0.028)$. The mechanical performance of the mIPN3, mIPN4, and mIPN5 is shown in Figure 4B. These formulations which contain $1.0 \mathrm{mg} / \mathrm{mL} \mathrm{HA}$ and 7.0 to $8.0 \%$ w/w PEGDA $3.4 \mathrm{kDa}$ or $6.0 \mathrm{kDa}$ did not exhibit significant differences in terms of complex modulus when compared to MB tissue $(\mathrm{p} \geq 0.247)$. The complex modulus of scaffolds containing $\mathrm{HA}$ at $2.0 \mathrm{mg} / \mathrm{mL}$ and $3.4 \mathrm{kDa}$ PEGDA at 7.0 to $8.0 \% \mathrm{w} / \mathrm{w}$ is presented in Figure 4C. In this series mIPN, formulations containing $3.4 \mathrm{kDa}$ PEGDA levels at $8.0 \% \mathrm{w} / \mathrm{w}$ or higher concentration displayed significantly higher values of complex modulus when compared to MB tissue $(p=0.003)$. Finally, Figure 4D summarizes the mechanical performance of three mIPN formulations exhibiting similar complex modulus to that measured in $\mathrm{MB}(\approx 6.9 \mathrm{kPa})$, while allowing the modulation of the HA content from 0.0 
to $2.0 \mathrm{mg} / \mathrm{mL}$. These findings are very significant since, by modulating the $\mathrm{MW}$ and concentration of PEGDA, the mechanical properties of the mIPNs can be adjusted to mimic the modulus of brain tissue while the content of biochemical cues such as HA can be varied. Differences in the biochemical content in the mIPNs can then be used to study processes such as tissue degradation or tissue scarring.

Thus far, we have demonstrated that the chemical composition of the bioinspired mIPNs can be modulated to achieve a family of materials exhibiting complex moduli within a relevant range of values of CNS tissue. While the presence of Col I and HA provides biochemical cues, PEGDA was introduced to maintain mechanical stability and to limit cell-mediated contraction and degradation ${ }^{17}$. Our final goal was to highlight that our fabrication procedure resulted in a cytocompatible system that supports the 3D in vitro culture of human neural stem cell, astrocytes and microglia. Toward this end, the Live/Dead viability assay (Invitrogen) was performed $24 \mathrm{~h}$ post cell encapsulation in the mIPN7 formulation as shown in Figure 5. At least four regions from four independent specimens were imaged using a laser Nikon A1 confocal microscope system. Cell counts were obtained using Image J and the viability reported as the ratio between living cells and the total number of cells (Figure 5A). Representative images of the cell viability assay are reported in Figure 5B. Cell viability for iHNSCs, HAf, and HMC3 24 h post scaffold fabrication was $84 \%, 93 \%$, and $89 \%$ respectively. The viability of the iHNSCs was the lowest among the three evaluated cell types. This observation can be explained if we consider that stem cells are more sensitive than non-stem cells, and that they require very specific substrates and cell culture conditions for their growth and maintenance. The viability of the scaffolds could be further enhanced by introducing additional ECM components such as laminin or laminin-based peptide sequences ${ }^{29}$. The overall viability results demonstrated that the mIPNs are very promising scaffolds which can sustain at least $84 \%$ cell viability. These results are within the range of values previously reported for hydrogel based systems ${ }^{30}$. 
Cumulatively, we have demonstrated that in the proposed family of mIPNs the chemical composition can be adjusted to achieve complex moduli within the range of mechanical properties of CNS tissue. The SEM characterization, PR and AB staining, and absorbance spectroscopy confirmed the incorporation of the three components. Finally, encapsulated human astrocytes, microglia, and neural stem cells exhibited very good viability values which exceed $84 \%$. We believe that this proposed platform could potentially be used as an in vitro $3 \mathrm{D}$ model for studying the physiology and the progression of pathologies associated with three of the main cells types in the CNS. In addition, we also envision that the 3D context provided by the mIPNs could potentially aid in understanding some of the molecular mechanisms responsible for the production and accumulation of ECM components, such as amyloid beta and the tau protein, and their effects on the behavior of neuron-like cells, astrocytes, and microglia. Moreover, since the presence of Col I has been associated with astrocyte reactivity and HA with the promotion of quiescent astrocytes ${ }^{23}$, the fine tuning of the Col I-HA ratio in the scaffolds could be used to study glial scar formation. Therefore, our mIPNs offer the opportunity to study the astrocyte reactivity that is characteristic of the brain inflammation preceding and during AD neurodegeneration. In summary, the continuous development of these novel scaffolds will be of great interest to the neuroscience and the Alzheimer's research community.

\section{Acknowledgments}

This work was supported by a grant from the Alzheimer's Association and Alzheimer's Texas (AARGD17-531470), the Trinity University Murchison research fellowship and the Trinity University start up fund. 


\section{References}

(1) Sances, S.; Bruijn, L. I.; Chandran, S.; Eggan, K.; Ho, R.; Klim, J. R.; Livesey, M. R.; Lowry, E.; Macklis, J. D.; Rushton, D. Modeling ALS with Motor Neurons Derived from Human Induced Pluripotent Stem Cells. Nat. Neurosci. 2016, 19 (4), 542-553.

(2) Liang, W. S.; Dunckley, T.; Beach, T. G.; Grover, A.; Mastroeni, D.; Ramsey, K.; Caselli, R. J.; Kukull, W. A.; McKeel, D.; Morris, J. C. Altered Neuronal Gene Expression in Brain Regions Differentially Affected by Alzheimer's Disease: A Reference Data Set. Physiol. Genomics 2017, 33, $240-256$.

(3) Jo, S.; Yarishkin, O.; Hwang, Y. J.; Chun, Y. E.; Park, M.; Woo, D. H.; Bae, J. Y.; Kim, T.; Lee, J.; Chun, H. GABA From Reactive Astrocytes Impairs Memory in Mouse Models of Alzheimer's Disease. Nat. Med. 2014, 20 (8), 886-896.

(4) Gontier, G.; George, C.; Chaker, Z.; Holzenberger, M.; Aïd, S. Blocking IGF Signaling in Adult Neurons Alleviates Alzheimer's Disease Pathology Through Amyloid-B Clearance. J. Neurosci. 2015, 35 (33), 11500-11513.

(5) Kim, H. G.; Ju, M. S.; Kim, D. H.; Hong, J.; Cho, S. H.; Cho, K. H.; Park, W.; Lee, E. H.; Kim, S. Y.; Oh, M. S. Protective Effects of Chunghyuldan Against ROS-Mediated Neuronal Cell Death in Models of Parkinson's Disease. Basic Clin. Pharmacol. Toxicol. 2010, 107 (6), 958-964.

(6) Paşca, A. M.; Sloan, S. A.; Clarke, L. E.; Tian, Y.; Makinson, C. D.; Huber, N.; Kim, C. H.; Park, J.-Y.; O'Rourke, N. A.; Nguyen, K. D.; Smith, S. J.; Huguenard, J. R.; Geschwind, D. H.; Barres, B. A.; Paşca, S. P. Functional Cortical Neurons and Astrocytes from Human Pluripotent Stem Cells in 3D Culture. Nat. Methods 2015, 12, 671-678.

(7) Baker, B. M.; Chen, C. S. Deconstructing the Third Dimension-How 3D Culture Microenvironments Alter Cellular Cues. J. Cell Sci. 2012, 125 (13), 3015-3024.

(8) Bloom, G. S. Amyloid-B and Tau: The Trigger and Bullet in Alzheimer Disease Pathogenesis. JAMA Neurol. 2014, 71 (4), 505-508.

(9) Wang, L.; Benzinger, T. L.; Su, Y.; Christensen, J.; Friedrichsen, K.; Aldea, P.; McConathy, J.; Cairns, N. J.; Fagan, A. M.; Morris, J. C. Evaluation of Tau Imaging in Staging Alzheimer Disease and Revealing Interactions Between B-Amyloid and Tauopathy. JAMA Neurol. 2016, 73 (9), 10701077.

(10) Kraning-Rush, C. M.; Carey, S. P.; Califano, J. P.; Smith, B. N.; Reinhart-King, C. A. The Role of the Cytoskeleton in Cellular Force Generation in 2D and 3D Environments. Phys. Biol. 2011, 8 (1), 015009.

(11) Yilmaz, N. D. Multicomponent, Semi-Interpenetrating-Polymer-Network and InterpenetratingPolymer-Network Hydrogels: Smart Materials for Biomedical Applications. In Functional Biopolymers, Springer 2018, 281-342.

(12) Cantley, W. L.; Du, C.; Lomoio, S.; DePalma, T.; Peirent, E.; Kleinknecht, D.; Hunter, M.; TangSchomer, M. D.; Tesco, G.; Kaplan, D. L. Functional and Sustainable 3D Human Neural Network Models from Pluripotent Stem Cells. ACS Biomater. Sci. Eng. 2018, 4, 4278-4288.

(13) Frampton, J.; Hynd, M.; Shuler, M.; Shain, W. Fabrication and Optimization of Alginate Hydrogel Constructs for Use in 3D Neural Cell Culture. Biomed. Mater. 2011, 6 (1), 015002.

(14) Kennea, N. L.; Mehmet, H. Neural Stem Cells. J. Pathol. 2002, 197 (4), 536-550.

(15) Hopkins, A. M.; DeSimone, E.; Chwalek, K.; Kaplan, D. L. 3D in Vitro Modeling of the Central Nervous System. Prog. Neurobiol. 2015, 125, 1-25. 
(16) Moshayedi, P.; Carmichael, S. T. Hyaluronan, Neural Stem Cells and Tissue Reconstruction After Acute Ischemic Stroke. Biomatter 2013, 3 (1), e23863.

(17) Munoz-Pinto, D. J.; Jimenez-Vergara, A. C.; Gharat, T. P.; Hahn, M. S. Characterization of Sequential Collagen-Poly (Ethylene Glycol) Diacrylate Interpenetrating Networks and Initial Assessment of Their Potential for Vascular Tissue Engineering. Biomaterials 2015, 40, 32-42.

(18) Jimenez-Vergara, A. C.; Lewis, J.; Hahn, M. S.; Munoz-Pinto, D. J. An Improved Correlation to Predict Molecular Weight Between Crosslinks Based on Equilibrium Degree of Swelling of Hydrogel Networks. J. Biomed. Mater. Res., Part B 2018, 106 (3), 1339-1348.

(19) Buxton, A. N.; Zhu, J.; Marchant, R.; West, J. L.; Yoo, J. U.; Johnstone, B. Design and Characterization of Poly (Ethylene Glycol) Photopolymerizable Semi-Interpenetrating Networks for Chondrogenesis of Human Mesenchymal Stem Cells. Tissue Eng. 2007, 13 (10), 2549-2560.

(20) Cruise, G. M.; Scharp, D. S.; Hubbell, J. A. Characterization of Permeability and Network Structure of Interfacially Photopolymerized Poly (Ethylene Glycol) Diacrylate Hydrogels. Biomaterials 1998, 19 (14), 1287-1294.

(21) Lin, S.; Sangaj, N.; Razafiarison, T.; Zhang, C.; Varghese, S. Influence of Physical Properties of Biomaterials on Cellular Behavior. Pharm. Res. 2011, 28 (6), 1422-1430.

(22) Raub, C. B.; Suresh, V.; Krasieva, T.; Lyubovitsky, J.; Mih, J. D.; Putnam, A. J.; Tromberg, B. J.; George, S. C. Noninvasive Assessment of Collagen Gel Microstructure and Mechanics Using Multiphoton Microscopy. Biophys. J. 2007, 92 (6), 2212-2222.

(23) Placone, A. L.; McGuiggan, P. M.; Bergles, D. E.; Guerrero-Cazares, H.; Quiñones-Hinojosa, A.; Searson, P. C. Human Astrocytes Develop Physiological Morphology and Remain Quiescent in a Novel 3D Matrix. Biomaterials 2015, 42, 134-143.

(24) Skaalure, S. C.; Dimson, S. O.; Pennington, A. M.; Bryant, S. J. Semi-Interpenetrating Networks of Hyaluronic Acid in Degradable PEG Hydrogels for Cartilage Tissue Engineering. Acta Biomater. 2014, 10 (8), 3409-3420.

(25) Kutty, J. K.; Cho, E.; Lee, J. S.; Vyavahare, N. R.; Webb, K. The Effect of Hyaluronic Acid Incorporation on Fibroblast Spreading and Proliferation within PEG-Diacrylate Based SemiInterpenetrating Networks. Biomaterials 2007, 28 (33), 4928-4938.

(26) Fairbanks, B. D.; Schwartz, M. P.; Bowman, C. N.; Anseth, K. S. Photoinitiated Polymerization of PEG-Diacrylate with Lithium Phenyl-2, 4, 6-Trimethylbenzoylphosphinate: Polymerization Rate and Cytocompatibility. Biomaterials 2009, 30 (35), 6702-6707.

(27) Frazier, S. B.; Roodhouse, K. A.; Hourcade, D. E.; Zhang, L. The Quantification of Glycosaminoglycans: A Comparison of HPLC, Carbazole, and Alcian Blue Methods. Open Glycosci. 2008, 1, 31-39.

(28) Durst, C. A.; Cuchiara, M. P.; Mansfield, E. G.; West, J. L.; Grande-Allen, K. J. Flexural Characterization of Cell Encapsulated PEGDA Hydrogels with Applications for Tissue Engineered Heart Valves. Acta Biomater. 2011, 7 (6), 2467-2476.

(29) Koh, H.; Yong, T.; Chan, C.; Ramakrishna, S., Enhancement of neurite outgrowth using nanostructured scaffolds coupled with laminin. Biomaterials 2008, 29 (26), 3574-3582.

(30) Thonhoff, J. R.; Lou, D. I.; Jordan, P. M.; Zhao, X.; Wu, P. Compatibility of Human Fetal Neural Stem Cells with Hydrogel Biomaterials In Vitro. Brain Res. 2008, 1187, 42-51. 

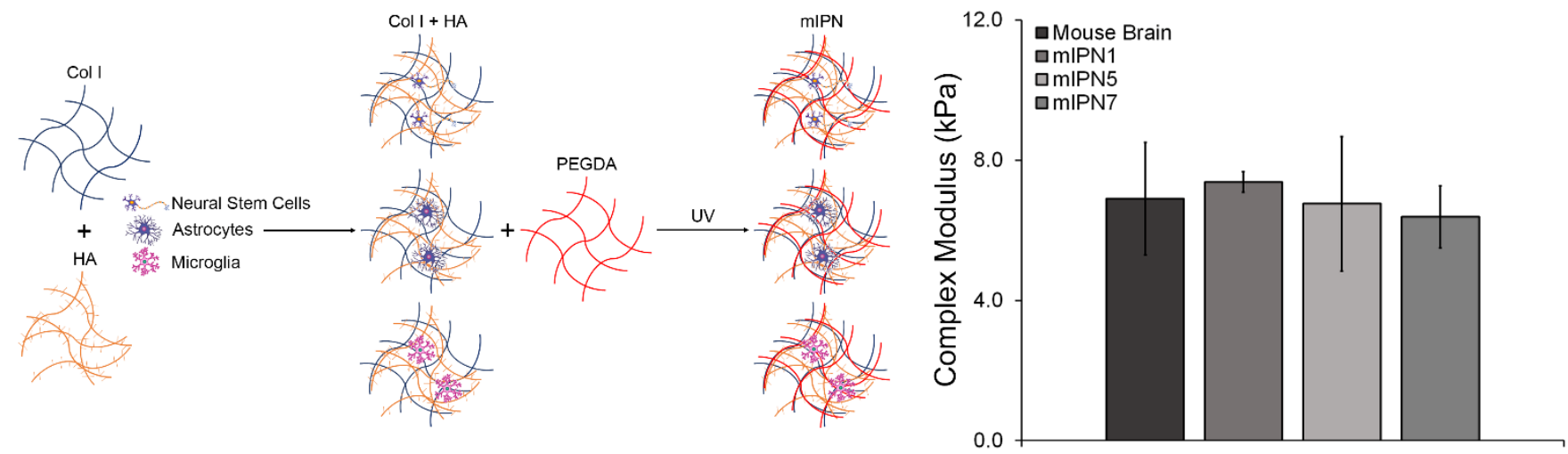

\section{Graphical Abstract.}

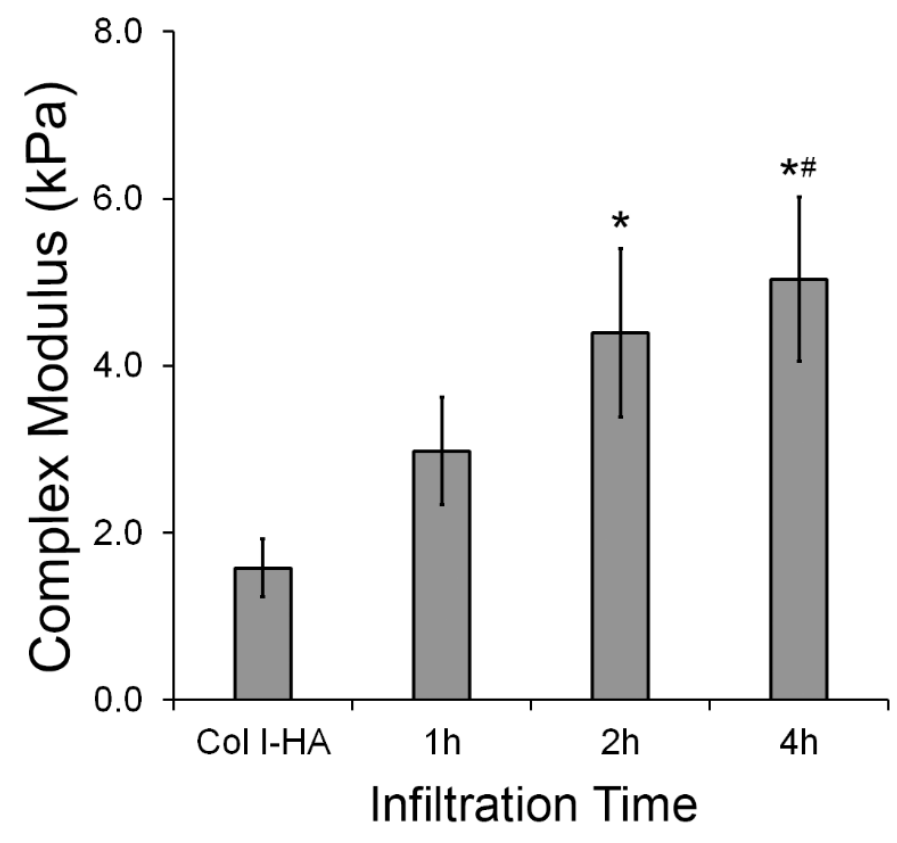

Figure 1. Effects of infiltration time on mIPN complex modulus. * Significantly different from Col I-HA, $\mathrm{p}<0.05$; " significantly different from $1 \mathrm{~h}$ infiltration time, $\mathrm{p}<0.05, \mathrm{n}=4$. 

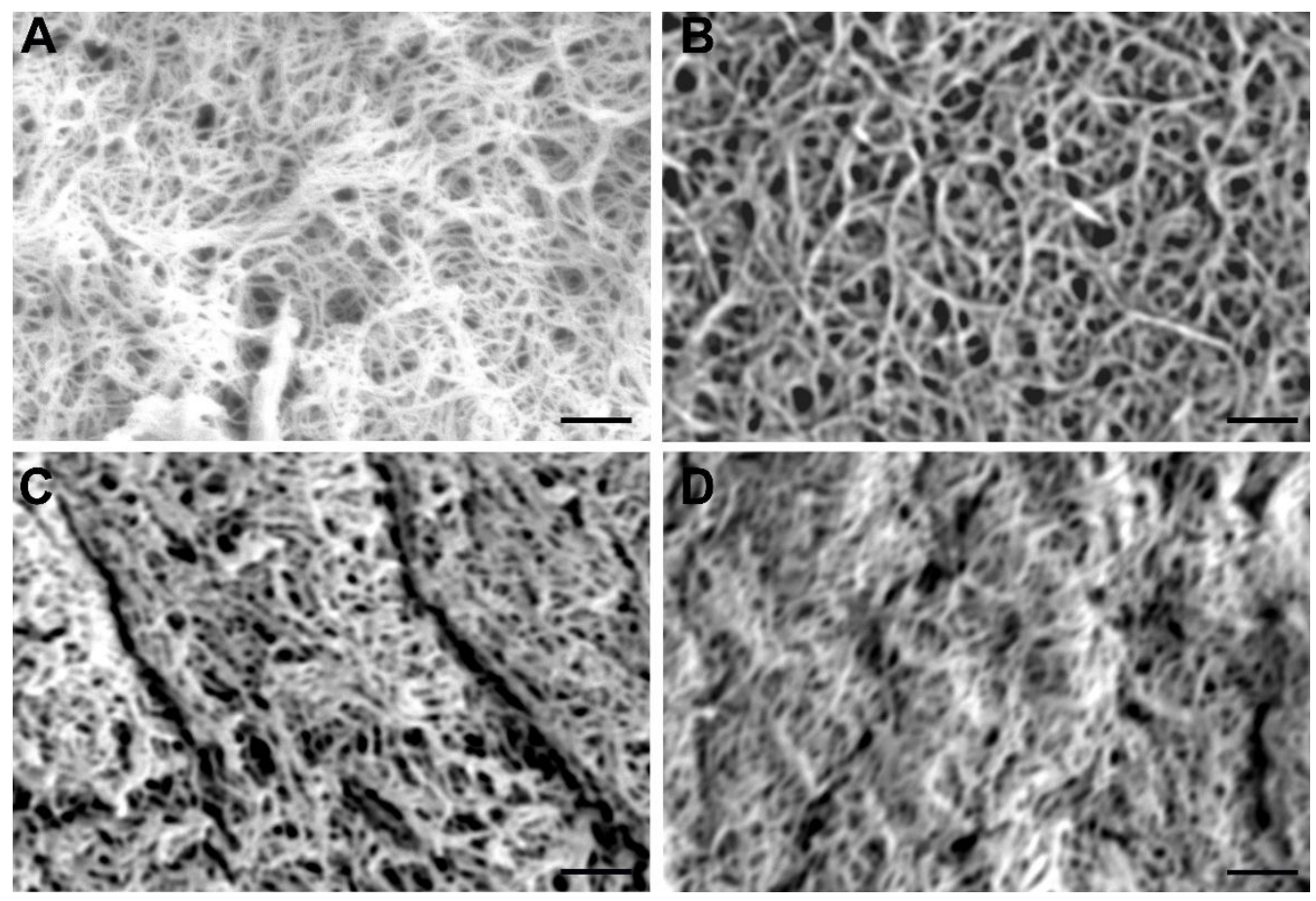

Figure 2. Representative SEM micrographs of scaffold microstructures. (A) Pure Col I. (B) Pure 3.4 kDa PEGDA. (C) Col I-PEGDA scaffold. (D) Col I-HA-PEGDA mIPN7. Images were taken at 7,000x magnification, scale bar $=1 \mu \mathrm{m}, \mathrm{n}=5$. 


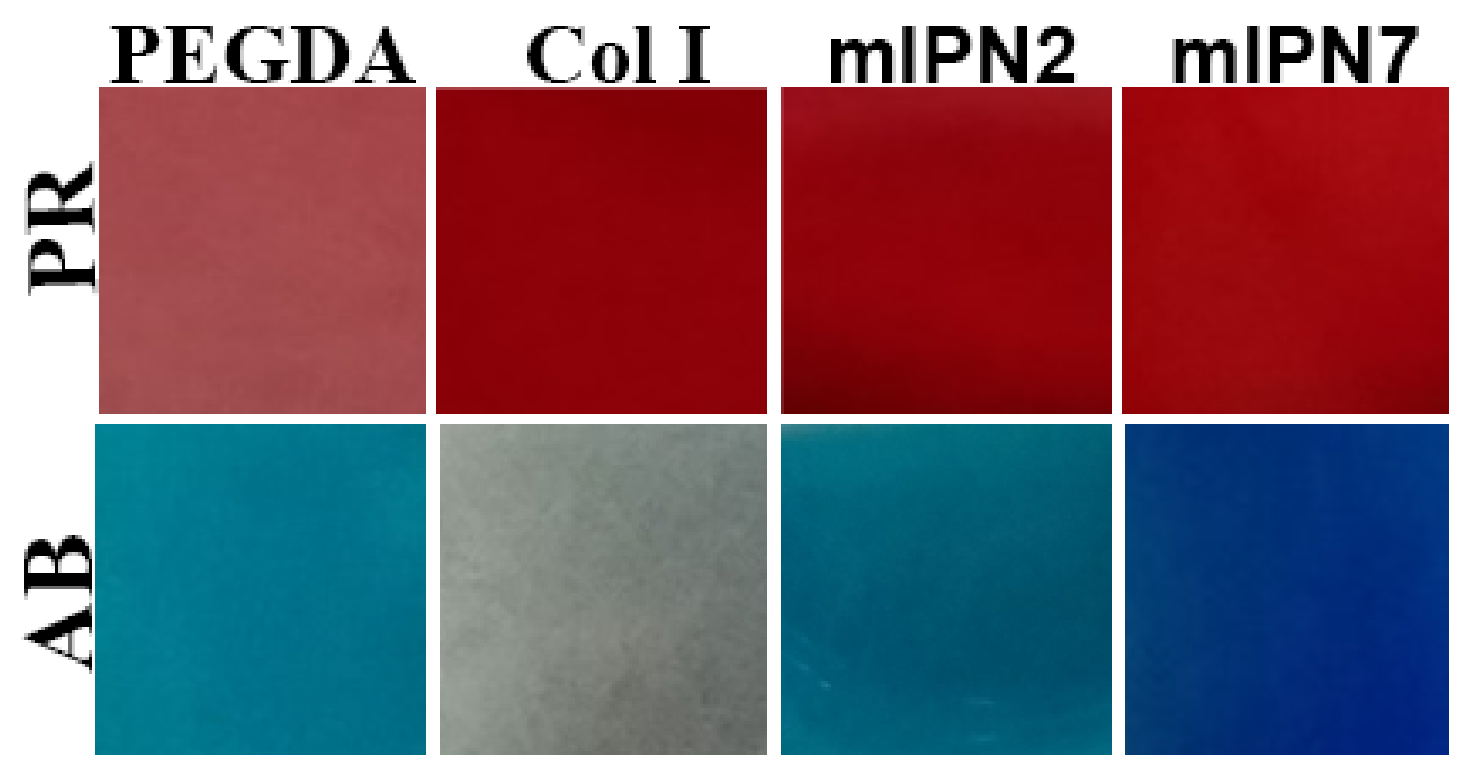

Figure 3. Representative images of Picrosirius Red (PR) and Alcian Blue (AB) staining of pure $3.4 \mathrm{kDa}$ PEGDA, Col I, mPIN2 (0.0 mg/mL HA) and mIPN7 (2.0 mg/mL HA). 


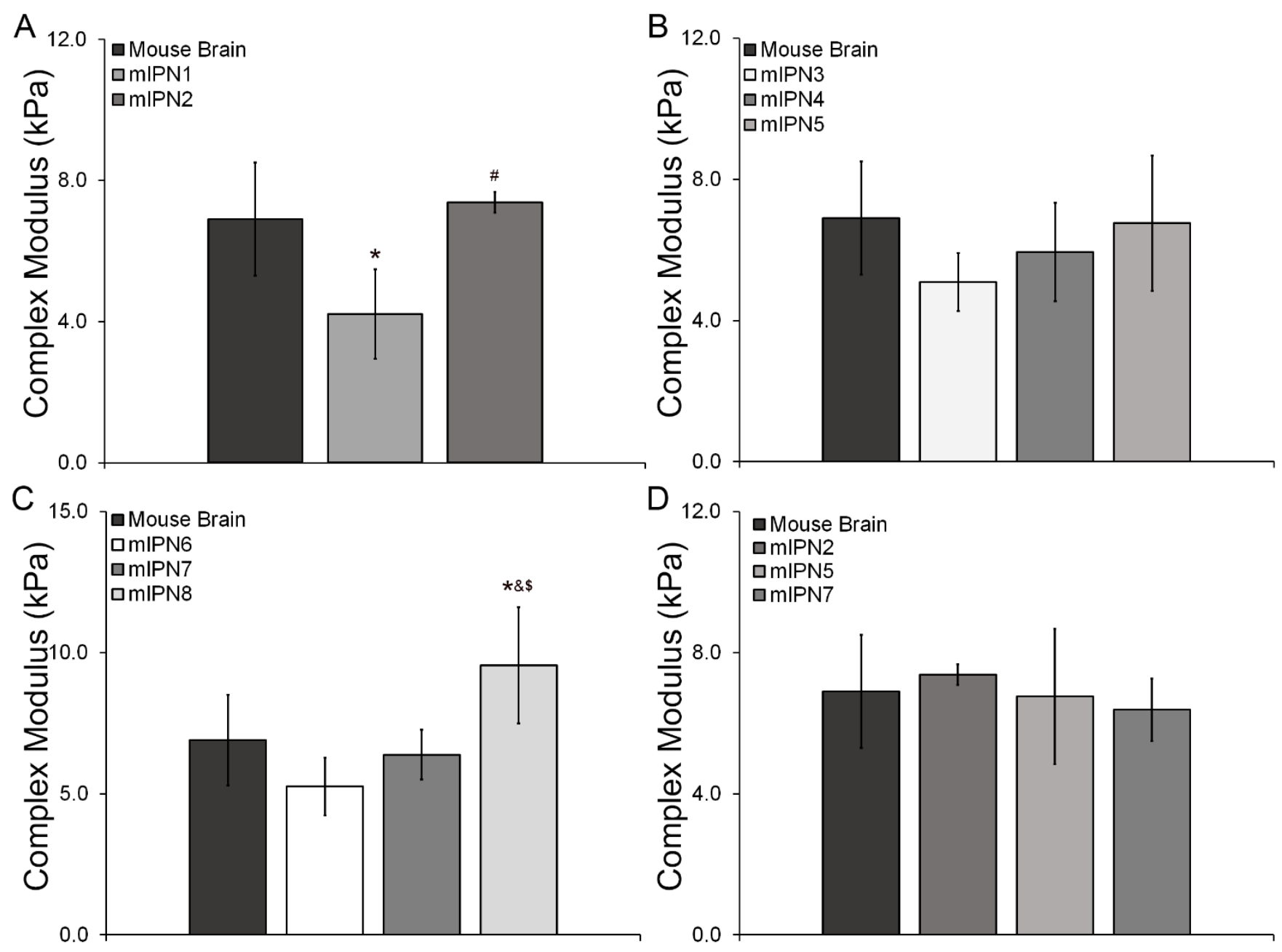

Figure 4. Effects of composition on mIPN complex modulus. (A) mIPNs containing $0.0 \mathrm{mg} / \mathrm{mL}$ HA. (B) mIPNs containing $1.0 \mathrm{mg} / \mathrm{mL}$ HA. (C) mIPNs containing $2.0 \mathrm{mg} / \mathrm{mL}$. (D) Selected mIPNs of varying composition displaying values of complex modulus similar to that in mouse brain tissue. Data are reported as average plus or minus the standard deviation; *, significantly different from mouse brain, $\mathrm{p}<0.05$; \#, significantly different from mIPN1, $\mathrm{p}<0.05$; \& , significantly different from mIPN6, $\mathrm{p}<0.05 ;$, significantly different from mIPN7; the absence of marks over the experimental groups indicates that differences among them are not statistically significant $(\mathrm{p} \geq 0.05), \mathrm{n}=5$. 


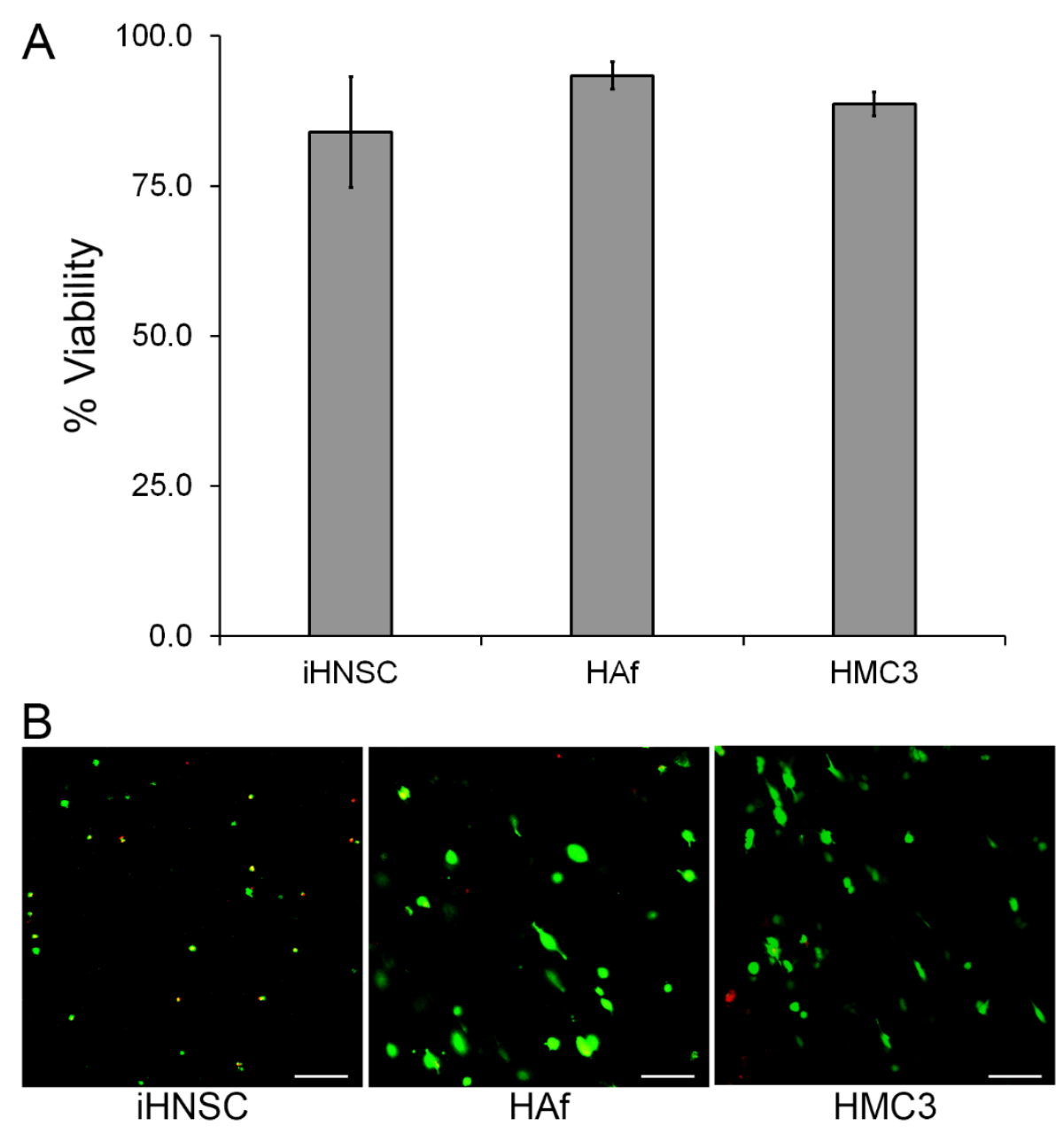

Figure 5. Cell viability of iHNSC, HAf, and HMC3 after 1 day of culture in mIPN7. (A) Quantitative results using ImageJ software. (B) Representative laser scanning confocal microscopy images of Live/Dead staining, $n=4$. 
Table 1. Chemical composition of mIPNs.

\begin{tabular}{lcccc}
\hline mIPN & $\begin{array}{c}\text { Collagen } \\
\text { concentration } \\
(\mathrm{mg} / \mathrm{mL})\end{array}$ & $\begin{array}{c}\text { HA } \\
\text { concentration } \\
(\mathrm{mg} / \mathrm{mL})\end{array}$ & $\begin{array}{c}\text { PEGDA } \\
\text { molecular } \\
\text { weight }(\mathrm{kDa})\end{array}$ & $\begin{array}{c}\text { PEGDA } \\
\text { concentration } \\
(\% \mathrm{w} / \mathrm{w})\end{array}$ \\
\hline mIPN1 & 3.0 & 0.0 & 20.0 & 7.0 \\
mIPN2 & 3.0 & 0.0 & 10.0 & 7.0 \\
mIPN3 & 3.0 & 1.0 & 6.0 & 7.0 \\
mIPN4 & 3.0 & 1.0 & 6.0 & 8.0 \\
mIPN5 & 3.0 & 1.0 & 3.4 & 7.0 \\
mIPN6 & 3.0 & 2.0 & 3.4 & 7.0 \\
mIPN7 & 3.0 & 2.0 & 3.4 & 7.5 \\
mIPN8 & 3.0 & 2.0 & 3.4 & 8.0 \\
\hline
\end{tabular}

